\title{
O CONTO DO CANÁRIO E OS PARADIGMAS HERMENÊUTICOS: DO POSITIVISMO NORMATIVISTA DE HANS KELSEN AO DIREITO COMO INTEGRIDADE DE RONALD DWORKIN
}

Bruno Taufner Zanotti ${ }^{1}$

Elda Coelho De Azevedo Bussinguer ${ }^{2}$

\section{RESUMO}

O estudo do positivismo jurídico consiste em um necessário pressuposto para entender a atuação de alguns magistrados. Ir além dos déficits metodológicos inerentes ao positivismo é o contexto no qual se insere o presente artigo que busca responder ao seguinte problema: De que forma é possível reconstruir metodologicamente o Direito a partir de uma teoria que não se limite à plenipotenciariedade da regra? Concluiu-se que é necessário abandonar o positivismo jurídico e superar a pretensão de se separar o estudo do Direito das análises axiológicas de modo a possibilitar a construção dessa ciência com um fundamento valorativo.

PALAVRAS-CHAVE: Paradigmas, Positivismo, Hans Kelsen, Pós-positivismo, Ronald Dworkin

\section{THE CANARY TALE AND THE HERMENEUTICAL PARADIGMS: FROM HANS KELSEN'S NORMATIVISM POSITIVISM TO THE RONALD DWORKIN'S LAW AS INTEGRITY}

\begin{abstract}
The study of the positivism can be considered as a necessary presupposition to understand the application of Law. To go beyond the methodological deficits of the positivism is the context in which the present article is inserted, which seeks to answer the following question: How can Law be methodological reconstructed from a theory that is not limited by the plenipotentiary of the rule? It was verified that it is necessary to abandon positivism and overcome the pretension to separate the study of law from axiological analyzes in order to enable the construction of this science with an value foundation.
\end{abstract}

Keywords: Paradigms. positivism, Hans Kelsen, Post-positivism, Ronald Dworkin

\section{INTRODUÇÃO}

Joaquim Maria Machado de Assis representa um dos grandes nomes da literatura brasileira. No conto "Ideias do Canário", o autor trabalha com uma situação peculiar e demonstra como o ser humano é limitado pelo mundo pré-fabricado no qual está inserido. $\mathrm{O}$

\footnotetext{
${ }^{1}$ Doutorando e Mestre em Direitos e Garantias Fundamentais pela Faculdade de Direito de Vitória (FDV). Professor da Pós-Graduação Lato Sensu da Associação Espírito-Santense do Ministério Público. E-mail brunotaufner@hotmail.com

${ }^{2}$ Livre Docente pela UNI- RIO- Universidade do Rio de Janeiro, Doutora em Bioética pela UnB, Mestre em Direito pela FDV, Coordenadora do PPGD da FDV. E-mail - elda.cab@gmail.com
} 
caráter temporal e precário do homem torna difícil reconhecer o esgotamento de determinada concepção de mundo a fim de que possa buscar um novo horizonte de possibilidades.

No Direito, essa situação não é diferente. O estudo da sentença é capaz de desvelar visões paradigmáticas conflitantes e temporais que, ainda hoje, condicionam a atuação dos magistrados, mas que não se mostram adequadas à noção do Estado Democrático de Direito.

Essa afirmativa decorre da adoção expressa por alguns magistrados do positivismo jurídico $^{3}$, visão do Direito fruto do Estado Social, supostamente neutra e impregnada por decisionismos e discricionariedades incompatíveis com o Estado Democrático de Direito. Ir além desses déficits metodológicos inerentes ao positivismo é o contexto no qual se insere o presente artigo e o estudo busca responder ao seguinte problema: De que forma é possível reconstruir metodologicamente o Direito a partir de uma teoria que não se limite à plenipotenciariedade da regra?

Para responder o questionamento, inicialmente, será exposto o conceito de paradigma e sua relação com o conto "Ideias do Canário", de Joaquim Maria Machado de Assis. Em seguida, será estudada a proposta metodológica do positivismo de Hans Kelsen e a sua evolução ao longo dos anos para, ao final e a partir de Ronald Dworkin, apresentar uma proposta do Direito mais adequada aos pressupostos de um Estado Democrático de Direito.

Com a finalidade de melhor integrar as fontes de estudo a serem trabalhadas, verificouse a necessidade de uma abordagem hermenêutica. Por meio da interpretação das diversas obras, será possível responder ao problema levantado, de forma a possibilitar a análise de como uma hermenêutica equivocada é capaz de violar pressupostos do Estado Democrático de Direito.

\section{O CONTO DO CANÁRIO E A QUESTÃO DOS PARADIGMAS}

Analisar a história das instituições serve como importante premissa a fim de

\footnotetext{
3 "O direito é uma prudência, no âmbito da qual não se encontram respostas exatas, senão uma multiplicidade de respostas corretas. [...] A Constituição diz o que nós, juízes desta Corte, dizemos que ela diz. Nós transformamos em normas o texto escrito da Constituição [...]. Nós, aqui neste Tribunal, nós produzimos as normas que compõem a Constituição do Brasil hoje, agora. Nós é que, em derradeira instância, damos vida à Constituição, vivificamos a Constituição. E ela será do tamanho que a ela atribuirmos na amplitude dos nossos juízos." Voto do Ministro Eros Grau na ADI 4.219, julgada em 3/4/2009. Para uma análise completa sobre o tema, conferir o artigo "Póspositivismo jurídico e o direito como integridade de Ronald Dworkin" (COURA; ZANOTTI, 2014).
} 
demonstrar esquemas gerais de pré-compreensões que tornaram possível a vida em comunidade. No Direito, essa situação não é diferente. Desde a idade média, passando pelo Estado Liberal, pelo Estado Social e pelo Estado Democrático de Direito, é possível encontrar inúmeros autores com diferentes propostas metodológicas que buscaram compreender a aplicação do Direito em cada um desses paradigmas.

A proposta de Hans Kelsen, fruto do Estado Social, pode ser inserida nesse contexto e representa a busca por uma pureza científica, marcada pelo distanciamento do Direito com outros ramos sociais. Repensar essa metodologia importa, necessariamente, superar o Estado Social para que o Direito se abra ao mundo das complexas relações sociais, nas quais os princípios ganham relevância material para a concretização das práticas jurídicas.

Um paralelo com o conto "Ideias do Canário", de Joaquim Maria Machado de Assis, pode mostrar como o ser humano é limitado pelo mundo em que vive e, tal como os paradigmas, é influenciado, em sua conduta e modo de pensar, pelos limites e possibilidades do contexto no qual está inserido.

O conto narra uma situação na qual uma pessoa de nome Macedo adentra em uma loja de quinquilharias, atulhada de coisas velhas e administrada por um homem de idade avançada sem grandes ambições na vida. Ao cuidadosamente analisar o local, Macedo visualiza uma gaiola pendurada na porta com um pequeno canário dentro, que transbordava alegria e animação, capaz de dar um pequeno traço de vida àquele amontoado de destroços.

Perplexo com a situação de abandono ao qual fora jogado o canário, Macedo critica a indiferença com que alguma pessoa tratou o pássaro ao deixá-lo naquele local desprezível. Desenvolve-se, a partir daí, um diálogo entre Macedo e o canário. Macedo tenta mostrar ao pássaro a situação de penúria no qual estava inserido e o pouco cuidado que the era dado pelo seu dono, ao que recebe a seguinte resposta do canário:

\footnotetext{
Que dono? Esse homem que aí está é meu criado, dá-me água e comida todos os dias, com tal regularidade que eu, se devesse pagar-lhe os serviços, não seria com pouco; mas os canários não pagam criados. Em verdade, se o mundo é propriedade dos canários, seria extravagante que eles pagassem o que está no mundo.

$[\ldots]$

O mundo, redarguiu o canário com certo ar de professor, o mundo é uma loja de belchior, com uma pequena gaiola de taquara, quadrilonga, pendente de um prego; o canário é senhor da gaiola que habita e da loja que o cerca. Fora daí, tudo é ilusão e mentira (ASSIS).
}

Diante dessa resposta, Macedo decide comprar o canário e levá-lo para a sua casa, 
onde coloca o pássaro em uma gaiola mais ampla e pintada de branca, e pendura na varanda para que o mesmo pudesse ver o jardim e o céu azul. Três semanas após tal fato, Macedo pede para que o canário redefina o seu mundo:

O mundo, respondeu ele, é um jardim assaz largo com repuxo no meio, flores e arbustos, alguma grama, ar claro e um pouco de azul por cima; o canário, dono do mundo, habita uma gaiola vasta, branca e circular, donde mira o resto. Tudo o mais é ilusão e mentira (ASSIS).

Passado mais algum tempo, um dos empregados de Macedo esquece a gaiola aberta e o canário foge. Sem conseguir localizá-lo, Macedo se entristece com a situação até que, meses após tal fato, durante uma caminhada em uma bela chácara, encontra, mais uma vez, com o canário e o chama para conversar no antigo "mundo dos dois", formado pelo jardim, pela varanda e pela gaiola branca. Diante desse convite, o canário questiona o conceito de mundo de Macedo e apresenta uma nova resposta: "Que mundo? Tu não perdes os maus costumes de professor. O mundo, concluiu solenemente, é um espaço infinito e azul, com o sol por cima" (ASSIS).

Note a evolução "dos mundos" do canário de acordo com a evolução do conto e o modo pelo qual a sua leitura desses mundos é norteada pela compreensão do contexto no qual ele está inserido. Cada um dos três momentos vividos pelo canário pode ser analisado como um distinto paradigma, uma vez que condiciona as respostas dadas pelo pássaro.

Um paradigma pode ser visualizado como conceitos prévios de um mundo, capaz de nortear a leitura que dele se faz e capaz de limitar a compreensão que se tem desse mundo. Trata-se de uma leitura precária por ser sempre contextualizada pelo tempo e pelo lugar e é nesse contexto que se insere a seguinte afirmativa de Bauman (1997, p. 17):

nenhum de nós pode construir o mundo das significações e sentidos a partir do nada: cada um ingressa num mundo 'pré-fabricado', em que certas coisas são importantes e outras não o são; em que as conveniências estabelecidas trazem certas coisas para a luz e deixam outras na sombra.

Contudo, um paradigma não é somente o que os membros de uma comunidade partilham (aspecto objetivo), mas, também, é um conjunto de pessoas que partilham esse mundo 
pré-fabricado (aspecto subjetivo). Daí decorre o caráter circular do paradigma ressaltado por Thomas Kuhn (2001, p. 219).

Kuhn (2001, p. 220) enfatiza a existência de paradigmas em esferas restritas de compreensão das ciências ou mesmo em esferas sociais de menor abrangência. $\mathrm{O}$ autor trata do exemplo da linguagem utilizada por determinada especialidade científica, ao argumento de que certo ramo da ciência possui linguagem e ensinamentos próprios, tornando a comunicação difícil com pessoas que estejam fora desse círculo hermenêutico-paradigmático.

Isso ocorre porque, como mencionado acima, o paradigma possui um duplo aspecto ao limitar e nortear a leitura do mundo. No que diz respeito ao primeiro aspecto, Menelick de Carvalho Netto (1999, p. 476) afirma que o paradigma

[...] possibilita explicar o desenvolvimento científico como um processo que se verifica mediante rupturas, através da tematização e explicitação de aspectos centrais dos grandes esquemas gerais de pré-compreensões e visões-de-mundo, consubstanciados no pano-de-fundo naturalizado de silêncio assentado nas gramáticas das práticas sociais, que a um só tempo tornam possível a linguagem, a comunicação, e limitam ou condicionam o nosso agir e a nossa percepção de nós mesmos e do mundo.

Em outras palavras, o primeiro aspecto do paradigma, ao limitar a leitura do mundo, torna possível a comunicação e a convivência entre as pessoas inseridas no mesmo paradigma. Tais esferas gerais de pré-compreensões trazem em si determinado conteúdo que tenta perpetuar a idealidade utópica de cada paradigma, em especial por impor a conclusão de essa leitura ser a mais apropriada àquele tempo e espaço.

No que diz respeito ao segundo aspecto, nas palavras de Menelick de Carvalho Netto (1999, p. 476), o paradigma

[...] padece de óbvias simplificações, que só são válidas na medida em que permitem que se apresente essas grades seletivas gerais pressupostas nas visões de mundo prevalentes e tendencialmente hegemônicas em determinadas sociedades por certos períodos de tempo e em contextos determinados.

O segundo aspecto do paradigma pode ser traduzido como a visão limitada de um determinado contexto histórico-social. Apesar de a história ser muito mais rica e mais viva do que uma mera tentativa de simplificar determinado contexto ou período histórico, essa limitação é importante para que seja possível compreender a esfera de pré-compreensão em determinado tempo e local. 
Por isso, quando se trabalha com paradigmas hermenêuticos jurídicos, tal como o positivismo ou o pós-positivismo, não se busca exaurir suas características, mas, tão-somente, identificar prólogos silenciosos, que, ainda hoje, condicionam a intepretação do Direito e direcionam a metodologia a ser utilizada no caso concreto.

Tal como o canário de Machado de Assis, entender a evolução do contexto do mundo no qual estamos inseridos pode significar a necessidade de evolução do próprio pensamento positivista. Essa evolução requer um profundo aprendizado crítico do próprio ser humano, para que seja capaz de aceitar o esgotamento da visão de mundo no qual está inserido para, somente então, ser capaz de se reinventar para um novo mundo intersubjetivo da linguagem que seja construtivo, contestador e fraterno (DWORKIN, 2007, p. 492).

No entanto, nem todas as pessoas possuem a capacidade de transpor essa barreira teórica com importantes e significativos reflexos práticos. A resistência a esse processo é algo natural, em especial por requerer o auto reconhecimento da necessidade de se abandonar o que até então era aceito como correto e constitutivo de nós mesmos.

Essa reflexão é o que torna possível a humanidade viver em um novo horizonte de possibilidades, ao mesmo tempo em que também ela é limitada pelas sombras do novo mundo. É essa reflexão que acompanhou o canário e acompanhará a análise do positivismo kelseniano, as críticas que são a ele dirigidas e necessidade de sua superação pelo pós-positivismo jurídico.

\section{O POSITIVISMO KELSENIANO E A PUREZA DO DIREITO}

A Revolução Industrial e a Primeira Guerra Mundial possibilitaram o crescimento do viés social dos Estados, período conhecido como Estado Social, e a interpretação judicial, que até então era atribuição do Poder Legislativo, foi incorporada como condição de possibilidade para o exercício da magistratura (CAPPELLETTI, 1999, p. 41-43). Nesse período, acentuou-se o rompimento do Direito com a Moral e com outras ciências não jurídicas em razão do crescimento de diversos autores positivistas, como Hans Kelsen e Herbert Hart.

Uma das principais obras desse período histórico consiste no livro "Teoria Pura do Direito", escrito por Hans Kelsen. O próprio título da obra apresenta a busca do autor por uma pureza na ciência do Direito. Assim, Hans Kelsen demonstra sua preocupação com a autonomia da ciência jurídica e que essa proposta de visão do Direito não tem por fim analisar o que é

CONPEDI LAW REVIEW | Braga - Portugal | v. 3 | n. 2 | p. 182 - 201 | JUL/DEZ. 2017 
certo ou errado, o que é bom ou mau, mas, na verdade, busca estudar o que é válido ou inválido e o que é lícito ou ilícito. Essa ruptura entre a ciência do Direito e as demais ciências constitui a base sobre a qual Kelsen construiu a sua teoria:

\begin{abstract}
Quando a si própria se designa como "pura" Teoria do Direito, isto significa que ela se propõe garantir um conhecimento apenas dirigido ao Direito e excluir deste conhecimento tudo quanto não pertença ao seu objeto, tudo que não se possa, rigorosamente, determinar como Direito. Quer isto dizer que ela pretende libertar a ciência jurídica de todos os elementos que lhe são estranhos. Esse é o seu princípio metodológico fundamental. (KELSEN, 2003, p. 1)
\end{abstract}

Tal desvinculação é tão evidente em razão de o autor defender a validade de um direito positivo, mesmo na hipótese em que ele contrarie algum mandamento de justiça ou de moral. Dessa afirmação decorre o fato de que a validade do Direito tem por base um valor estritamente jurídico, ao passo que e a ética, a sociologia e outras ciências humanas não encontram espaço para dialogar com essa ciência pura:

Quanto a Teoria Pura pretende delimitar o conhecimento do Direito em face destas disciplinas, fá-lo não por ignorar ou, muito menos, por negar essa conexão, por que intenta evitar um sincretismo metodológico que obscurece a essência da ciência jurídica e dilui os limites que lhe são impostos pela natureza do seu objeto. (KELSEN, 2003, p. 2)

Não se admite, portanto, qualquer relação do Direito com a Moral, de modo que um sistema que se intitule jurídico será regido exclusivamente por aspectos inerente à Ciência pura do Direito. Isso ocorre, pois um sistema jurídico que buscasse essa relação deveria se basear em uma moral absoluta e válida para todas as situações, algo impossível de ser alcançado:

\footnotetext{
A tese, rejeitada pela Teoria Pura do Direito, mas muito espalhada na jurisprudência tradicional, de que o Direito, segundo a sua própria essência, deve ser moral, de que uma ordem social imoral não é Direito, pressupõe, porém, uma moral absoluta, isto é, uma Moral válida em todos os tempos e em toda a parte. De outro modo ela não poderia alcançar o seu fim de impor a uma ordem social um critério de medida firme, independente de circunstâncias de tempo e de lugar, sobre o que é direito (justo) e o que é injusto. (KELSEN, 2003, p. 78)
}

Assim, a plenipotenciariedade da regra pode ser qualificada como fonte e pressuposto do sistema jurídico vigente, de modo a fechar o Direito para a amplitude normativa dos princípios e a sua relação com a moral e com os demais ramos científicos (STRECK, 2012a, p. 
59). A regra é fonte de legitimidade do Direito e imprescindível para a sua correta aplicação aos casos apresentados ao Poder Judiciário.

Dentro desse contexto se insere a concepção formal do Direito, de modo que a pureza de sua ciência sequer permitia um diálogo das normas com a realidade social ao qual ela seria dirigida. Existe uma prevalência da forma e do método com prejuízo do contexto social no qual o caso concreto está inserido (BOBBIO, 2006, p. 221-223).

Ao avançar com o positivismo normativista, Hans Kelsen introduz, pela via teórica, a opção para a atuação do Poder Judiciário, todas igualmente contempladoras das finalidades legais, cabendo ao aplicador a escolha de qualquer uma delas. De forma mais específica, houve uma cisão metodológica entre interpretação, a ser feita pelos cientistas do Direito, e aplicação do Direito, a ser feita pelos magistrados, as quais deveriam ocorrer em momentos distintos (KELSEN, 2003, p. 387-388).

Em cima dessa premissa, Kelsen trabalhou toda a sua teoria, a qual também tem por base uma necessária verticalização da hermenêutica, no sentido de que o processo de aplicação do Direito tem como ponto de partida um escalão normativo superior em direção a um escalão normativo inferior, v.g., na relação entre a Constituição e uma lei, ou entre uma lei e uma sentença. No entanto, essa conexão a priori é sempre indeterminada, já que a determinação de uma sentença ocorre somente após o julgamento pelo magistrado. Até então, o magistrado possui uma liberdade interpretativa, restringível, por assim dizer, pela pluralidade interpretativa decorrente da lei:

\footnotetext{
A norma de escalão superior não pode vincular em todas as direções (sob todos os aspectos) o ato através do qual é aplicada. Tem sempre de ficar uma margem, ora maior ora menor, de livre apreciação, de tal forma que a norma do escalão superior tem sempre, em relação ao ato de produção normativa ou de execução que aplica, o caráter de um quadro ou moldura a preencher por este ato. (KELSEN, 2003, p. 388)
}

A metodologia acima é exemplificada na hipótese em que um juiz emite um mandado de prisão para que a Polícia Civil prenda um determinado cidadão, sem delimitar as questões fáticas nas quais tal prisão será executada, como o dia, a hora e o local (KELSEN, 2003, p. 388). A indeterminabilidade prévia de tais informações é decorrência natural do sistema em razão de o magistrado não poder, de forma prévia, descrever detalhes do cumprimento de sua ordem e, portanto, o limite da interpretação será preenchido somente no momento da execução 
do mandado que impôs a medida restritiva de liberdade, mas dentro de uma moldura previamente determinada pelo juiz que delineia, pelo menos, a pessoa a ser presa, bem como os deveres e os direitos a serem observados.

No exemplo acima, é possível analisar o desencadeamento de conexões entre os diversos níveis do escalão normativo. Em primeiro lugar, a Constituição Federal regula, de forma bem ampla, as regras de criação das normas e os seus limites, mas atribui ao Poder Legislativo uma margem para a criação discricionária da lei. Em segundo lugar, a lei criada pelo Poder Legislativo prescreve inúmeras condutas - bem como as sanções - que devem ser observadas por todos e aplicadas pelo juiz dentro da moldura hermenêutica. Em terceiro lugar, o juiz, com base em seu poder discricionário, profere uma sentença, mas, mesmo assim, em alguns casos não restringe totalmente a interpretação da norma que cria, a qual ainda passará por mais um processo de interpretação no momento de sua aplicação, constituindo, essa, mais uma conexão entre os níveis do escalão normativo.

Observa-se, portanto, que o ponto em análise guarda relação com o limite interpretativo, ou seja, com a fixação de um determinado sentido ao objeto que se interpreta dentre vários igualmente aceitos e possíveis. Nesse contexto, do processo hermenêutico resultam várias interpretações que comporão a moldura, dentro da qual a escolha de qualquer uma delas pelo magistrado importará na criação do Direito positivo:

\footnotetext{
Se por interpretação se entende a fixação por via cognoscitiva do sentido do objeto a interpretar, o resultado de uma interpretação jurídica somente pode ser a fixação da moldura que representa o Direito a interpretar e, consequentemente, o conhecimento de várias possibilidades que dentro dessa moldura existem. Sendo assim, a interpretação não deve necessariamente conduzir a uma única solução como sendo a única correta, mas possivelmente a várias soluções que - na medida em que apenas sejam aferidas pela lei a aplica - têm igual valor, se vem que apenas uma delas se torne Direito positivo no ato do órgão aplicador do Direito. (KELSEN, 2003, p. 390 e 391).
}

Como afirma Carvalho Netto (1999, p. 481), os métodos de hermenêutica, v.g., a interpretação histórica, teleológica e sistêmica, concedem ao juiz uma multiplicidade discricionária interpretativa, desde que todos estejam dentro da moldura proposta por Kelsen.

Apesar de inúmeras interpretações possíveis da regra - que formariam a moldura -, Kelsen (2003, p. 391) afirma que não existe um critério pré-estabelecido para a escolha de uma interpretação correta: 
Não há absolutamente qualquer método - capaz de ser classificado como de Direito positivo - segundo o qual, das várias significações verbais de uma norma, apenas uma possa ser destacada como "correta" - desde que, naturalmente, se trate de várias significações possíveis: possíveis no confronto de todas as ouras normas da lei ou da ordem jurídica.

De tal visão cética, conclui-se que a inexistência de um critério importa, necessariamente, no uso da discricionariedade pelo magistrado ao aplicar a norma, de acordo com a sua conveniência e oportunidade, ao único argumento de que quem escolhe uma das interpretações está empossado no cargo de juiz. É por isso que a legitimidade da decisão do juiz positivista recai unicamente sob a sua autoridade, ou seja, pelo fato de estar investido da atividade jurisdicional.

Com isso, Hans Kelsen (2003, p. 393) qualifica como extrajurídica a problemática relativa à busca de "uma" interpretação mais adequada para o caso posto perante o magistrado, uma vez que, de acordo com a sua teoria, é o poder discricionário (a escolha de uma das interpretações) que tornará uma determinada interpretação jurídica como a interpretação correta:

A questão de saber qual é, de entre as possibilidades que se apresentam nos quadros do Direito a aplicar, a "correta", não é sequer - segundo o próprio pressuposto de que se parte - uma questão de conhecimento dirigido ao Direito positivo, não é um problema da teoria do Direito, mas um problema da política do Direito.

Na primeira edição da Teoria Pura do Direito de 1934, a escolha, pelo magistrado, de uma das interpretações inseridas na moldura se faz por meio de um ato de conhecimento. É por meio deste ato que se torna possível distinguir a interpretação jurídica feita pelo magistrado de qualquer outra interpretação feita pelos cientistas do Direito. De um lado, a interpretação dos cientistas jurídicos é capaz de ampliar a moldura de escolha do magistrado; contudo, é o poder discricionário do juiz que será capaz de transformar em Direito uma das interpretações, de modo a criar o Direito para o caso que lhe foi posto (COURA; AZEVEDO, 2014, p. 106-111).

Não obstante, no ano de 1960, foi publicada a terceira edição da obra Teoria Pura do Direito, consideravelmente ampliada e modificada quando comparada com a primeira edição de 1934. Isso ocorreu porque, em 1940, Kelsen mudou-se para os Estados Unidos, de modo a obter contato direto com a teoria dos precedentes, o que causou sensíveis alterações em sua obra: 
O contato posterior, nos Estados Unidos, nas Universidades de Harvard (1941-1942) e da Califórnia (1945), com o direito consuetudinário da Commom Law trouxe-lhe nova perspectiva e visão, passando Kelsen a considerar o direito de um modo mais plástico, fundado nos precedentes. (CRETELLA Jr.; CRETELLA, 2006, p. 18)

Dentre as inúmeras mudanças, ressaltam-se uma relacionada à hermenêutica jurídica:

A propósito importa notar que, pela via da interpretação autêntica, quer dizer, da interpretação de uma norma pelo órgão jurídico que a tem de aplicar, não somente se realiza uma das possibilidades reveladas pela interpretação cognoscitiva, da mesma norma, como também se pode produzir uma norma que se situe completamente fora da moldura que a norma a aplicar representa. (KELSEN, 2003, p. 394).

Alguns autores ${ }^{4}$ ignoram a assertiva acima ao afirmarem que tal frase seria apenas mais uma dentro de obra muito vasta e complexa, motivo pelo qual não se poderia dar uma relevância desproporcional a sua extensão. De fato, ao longo da obra, em nenhum outro momento Hans Kelsen trata ou aprofunda o tema; no entanto, isso não torna tais palavras menos relevantes na terceira edição da Teoria Pura do Direito.

Como se observa pela leitura do trecho supratranscrito, o autor enaltece a atividade judicial como aquela legítima e apta a criar o Direito. Mesmo que uma suposta norma se localize fora da moldura delineada pelos cientistas do Direito, ela será extraída dessa fonte não positiva, para, então, transmutar-se de conteúdo jurídico pelas mãos do agente investido da atividade jurisdicional, ou seja, o intérprete autêntico que é o magistrado.

Essa atividade judicial-criativa-legislativa não é qualificada por Kelsen (2003, p. 395) como um déficit de legitimidade de sua teoria ao argumento de que determinadas decisões judiciais não podem ser anuladas após o seu trânsito em julgado, em especial pelos tribunais de última instância, tornando jurídica uma norma até então eminentemente extrajurídica, que, inclusive, servirá de precedente para futuras decisões. São decisões supostamente incompatíveis com a ciência jurídica, mas, mesmo assim, válidas e aceitas dentro da Teoria Pura do Direito por se tornarem imutáveis em razão das regras do jogo processual.

Desse modo, Hans Kelsen introduz uma importante modificação em sua teoria e radicaliza a Teoria Pura do Direito. Isso ocorre porque a moldura não deixou de existir, mas, na verdade, ela continua em constante ampliação pelas mãos do magistrado. Cada nova decisão,

\footnotetext{
4 "Essa passagem tem provocado muita controvérsia entre os leitores de Kelsen. Ela pode ser compreendida como uma radicalização de suas noções e de seu pensamento. Isso levaria até mesmo, no limite, a uma posição que acabaria por colocar em xeque a própria ideia de um direito positivo. Por outro lado, pode-se também pensar que se trata apenas de uma frase em uma obra muito vasta. Isso implica dizer que não se poderia dar a essa frase um peso que parece desproporcional à sua extensão.” (BENJAMIN, SOUZA, p. 147-148)
} 
desde que tomada pelo magistrado fora da moldura, significa a sua própria ampliação em relação àquela previamente estabelecida.

Para adequar essa relevante alteração da hermenêutica positivista à sua teoria, Kelsen modifica outro ponto da obra na edição de 1960. A escolha da uma das interpretações da moldura que, até então, era uma mera atividade de cognição, ganha uma segunda natureza, qual seja, passa também a ser qualificada pelo autor como um ato de vontade (KELSEN, 2003, p. 393-395). Em razão dessa natureza híbrida, o juiz se transforma no próprio criador das normas, em especial porque a moldura passa a ser um mero parâmetro de análise e não mais o limite da atividade judicial.

Em outras palavras, essa profunda alteração paradigmática do pensamento de Hans Kelsen importa na conclusão de que qualquer decisão tomada pelo magistrado, mesmo que originariamente fora da moldura, seja juridicamente válida e aceita pelo ordenamento jurídico. O problema é que as decisões contrárias ao ordenamento jurídico passam a ser aceitas e toleradas pela Teoria Pura do Direito, desde que os instrumentos processuais não sejam utilizados para invalidar tais decisões e ocorra o trânsito em julgado da decisão:

\footnotetext{
No ano de 1960, em uma nova Teoria Pura do Direito, importantes modificações foram apresentadas por Kelsen no capítulo dedicado à interpretação jurídica. Tais inovações consubstanciaram um significativo giro na perspectiva kelseniana, na medida em que o autor reconheceu a impossibilidade de limitar o poder discricionário da autoridade competente para aplicar o Direito, o que acabou por colocar em risco os próprios objetivos da Teoria Pura, diluindo-a em puro decisionismo. (COURA, 2013, p. 133)
}

Portanto, o magistrado passa a ter uma verdadeira "carta branca" e as normas presentes na moldura nada mais são do que uma estratégia de julgamento que podem ser utilizadas (ou não) ao "bom" critério do magistrado. Essa análise se faz necessária porque o giro decisionista kelsensiano possibilita a constante utilização de parâmetros extrajurídicos pelo magistrado, como a moral, as questões sociais e as demais ciências. Desfaz-se, então, o mito da suficiência do Direito e a proposta do autor de criar uma suposta teoria "pura" do Direito, como se a limitação deste às regras, por si só, fosse suficiente para abraçar todas as complexas relações sociais.

De fato, a suposta legitimidade da decisão fora da moldura, admitida por Kelsen na terceira edição da obra Teoria Pura do Direito, pode ser vista como um déficit em sua teoria. 
No entanto, essa alteração da obra também pode ser entendida como a própria evolução do pensamento do autor, de modo a se verificar a impossibilidade de a ciência do Direito não trabalhar com questões extrajurídicas, como a moral e a sociologia. Essa importante mudança paradigmática reclama, necessariamente, o reconhecimento da limitação do positivismo como parâmetro hermenêutico e a necessidade de se buscar uma nova teoria para iluminar as futuras decisões.

\section{PÓS-POSITIVISMO EM RONALD DWORKIN E A RELEVÂNCIA DA MORAL}

Ronald Dworkin dá um importante passo, além da pretensão de uma pureza metodológica tão idealizada por Hans Kelsen, ao buscar na moral a legitimidade da decisão judicial. Com base nessa mudança paradigmática, Ronald Dworkin supera a pretensão de se separar o estudo do Direito das análises axiológicas de modo a construir a cientificidade de sua teoria em um fundamento valorativo. Para tanto, o autor (DWORKIN, 2012, p. 414) afirma que a relação entre o Direito e a Moral tem por base uma "estrutura em árvore", na qual o Direito é um ramo da moral política e a moral política é um ramo de um tronco ainda maior, qual seja, a moral.

Compreender o sentido político inerente ao Direito constitui um grande desafio em Ronald Dworkin, na medida em que se faz necessário despir de um conceito prévio - e até pejorativo - que a palavra "política" possui. Buscando romper esse senso comum, Ronaldo Porto Macedo Jr. (2014, p. 211-212) afirma que a ideia de política em Dworkin guarda relação com a existência de uma intencionalidade vinculada a uma demanda por legitimação moral para o exercício de qualquer poder.

Por isso, em “Justiça para Ouriços”, Dworkin está preocupado em expor de forma mais profunda a complexa relação entre moral e interpretação. Com a finalidade de consolidar sua teoria no plano prático, Ronald Dworkin (2012, p. 415 e 416) refuta o positivismo jurídico, que fundamenta a legitimidade dos atos exclusivamente em comportamentos históricos, e constrói a sua teoria com base no interpretativismo. A teoria reconhece a importância dos comportamentos históricos, desde que dentro de um constante diálogo com o papel a ser desempenhado pelos princípios de moral política.

Em outras palavras, em razão da adoção do interpretativismo, ganha relevância o romancista de Ronald Dworkin (2011, p. 23-72) que é, acima de tudo, preocupado não só com 
as regras e princípios atualmente presentes no ordenamento jurídico, mas, também, com a construção de uma complexa história da prática materialmente justificada por princípios voltados para um futuro que busca o Direito pela sua melhor luz:

O direito como integridade, portanto, começa no presente só se volta para o passado na medida em que seu enfoque contemporâneo assim o determine. Não pretende recuperar, mesmo para o direito atual, os ideais e os objetivos práticos dos políticos que o criaram. Pretende, sim, justificar o que eles fizeram em uma história geral digna de ser contada aqui, uma história que traz consigo uma afirmação complexa: a de que a prática atual pode ser organizada e justificada por princípios suficientemente atraentes para oferecer um futuro honrado (DWORKIN, 2007, p. 274).

O romancista não tem por finalidade reescrever o que cada integrante do Poder Legislativo ou do Poder Judiciário considerava essencial para a tomada de determinada decisão. Esses argumentos podem até ser considerados pelo romancista, mas ele não se prende em eventos isolados ou votos vencidos, uma vez que a história a ser contada não é de um indivíduo, mas da comunidade personificada (pessoa coletiva artificial):

\begin{abstract}
Em tal projeto, um grupo de romancistas escreve um romance em série; cada romancista interpreta os capítulos que recebeu para escrever um novo capítulo, que é então acrescentado ao que recebe o romancista seguinte, e assim por diante. Cada um deve escrever seu capítulo de modo a criar da melhor maneira possível o romance em elaboração, e a complexidade dessa tarefa reproduz a complexidade de decidir um caso difícil de direito como integridade (DWORKIN, 2007, p. 276).
\end{abstract}

É por isso que o conceito de moral política e a construção do direito como integridade não podem ser previamente estabelecidos com base em um conceito de equidade, liberdade ou devido processo legal. Eles devem ser construídos como expressão da história institucional da comunidade no qual ele está inserido que, ao mesmo tempo, reconstrói a prática do passado e possibilita a aplicação do Direito sob uma melhor luz.

Mais do que um modelo de julgamento, Ronald Dworkin constrói esse conceito de Direito como um projeto "para as pessoas que queremos ser e para a comunidade que pretendemos ter" (2007, p. 492). O fundamento moral do Direito demonstra a atitude de um julgador muito mais humano e bem menos metódico do que aquele desenvolvido por Hans Kelsen.

Nesse contexto, rompe-se com a separação entre interpretação da norma e a sua aplicação ao caso concreto, requisito de possibilidade do positivismo jurídico (GADAMER, 2004, p. 406-411). A interpretação é um fenômeno passível de ser feito somente em um caso 
concreto, no momento da aplicação do Direito, motivo pelo qual interpretar significa, necessariamente, aplicar o Direito (STRECK, 2012b).

Com a finalidade de superar as limitações metodológicas do positivismo jurídico, Ronald Dworkin (2012, p. 280) faz uso de uma moral Kantiana, ${ }^{5}$ a partir do que o autor classifica como "princípio de Kant”, assim conceituado:

Devemos mostrar respeito total pela igual importância objetiva da vida de todas as pessoas, mas também respeito total pela nossa própria responsabilidade de fazer algo de válido com as nossas vidas. Devemos interpretar a primeira exigência de maneira a deixar espaço para a segunda e vice-versa.

As duas exigências do princípio de Kant devem conviver em harmonia por serem vistos como expressão da relação entre a ética, responsável pelo "estudo de como viver bem" (DWORKIN, 2012, p. 25), e a moral, responsável pelo "estudo de como devemos tratar as outras pessoas" (DWORKIN, 2012, p. 25). Assim, obrigatoriamente, todas as pessoas têm uma responsabilidade pessoal pela própria vida, ou seja, uma responsabilidade que não se pode delegar e nem ignorar, ao passo que o princípio de Kant reclama o reconhecimento dessa responsabilidade paralela também na vida dos outros.

Nessa linha de pensamento, Ronald Dworkin (2012, p. 336) afirma que a moral política "estuda aquilo que todos nós devemos aos outros enquanto indivíduos, quando agimos em nome dessa pessoa coletiva artificial". De fato, o princípio de Kant impõe às pessoas a necessidade não só de cada indivíduo se engajar em um projeto que torne a sua vida a melhor vida possível, bem como impõe a necessidade de respeito pela importância objetiva da vida de todas pessoas.

É nesse contexto que o autor constrói a relação entre comunidade política e imposição de obrigações aos seus membros, sempre preocupado com a tensão entre os direitos da igualdade e da liberdade, cujos conceitos são reconstruídos a partir da matriz kantiana acima exposta que relaciona ética e moral no Direito:

Uma comunidade política só tem força moral para criar e impor obrigações aos seus membros, se os tratar com preocupação e respeito iguais, ou seja, se as suas políticas tratarem as vidas dos seus membros como igualmente importantes e respeitarem as

\footnotetext{
${ }^{5}$ A filosofia Kantiana é regida por imperativos categóricos e um deles institui que o cidadão age de tal modo que a máxima da sua ação deva se tornar uma lei universal: "age segundo máximas que possam ao mesmo tempo ser tomadas como objeto de si mesmas, como leis universais da natureza" (KANT, 2011, p. 67). A partir de uma moral racional, Kant impõe a ideia de que somente o ser humano pode reger a moral. Nesse contexto, o ser humano é a fonte do dever moral, dirigindo ele próprio a sua conduta. Dworkin (2012, p. 273) se apropria dessa ideia ao trabalhar diversos conceitos, como o de autonomia não como a liberdade de o ser humano fazer a sua própria vontade; mas como a ideia de o ser humano agir por respeito à lei moral kantiana, sem se preocupar com o fim particular. O conceito de liberdade, portanto, encontra-se vinculado ao agir pela lei moral.
} 
suas responsabilidades individuais sobre as próprias vidas. (DWORKIN, 2012, p. 338)

Pela citação, observa-se a existência de duas exigências para se consolidar a relação entre comunidade política e imposição de obrigações: por um lado, com um viés moral e fundamentado no direito da igualdade, as políticas devem tratar todos os membros como igualmente importantes; por outro lado, com um viés ético e fundamentado no direito da liberdade, as políticas devem respeitar as responsabilidades das pessoas por suas vidas.

Relaciona-se, desse modo, a moral política com os direitos da igualdade e da liberdade que são, acima de tudo, conceitos interpretativos e não criteriais. Não é possível pré-estabelecer critérios para a delimitação dos dois direitos fundamentais, cuja formulação parte da constante construção da história de certa comunidade e se verifica como uma prática melhor constrói essa comunidade de agora em diante.

Da mesma forma que Dworkin utiliza o princípio de Kant - e a relação entre ética e moral - para construir o conceito de moral política para, ao final, correlacionar a constante tensão entre a liberdade e a igualdade na construção desse conceito; a posterior construção pelo autor dos direitos à igualdade e à liberdade passa por esse mesmo fundamento teórico.

Ronald Dworkin (2012, p. 360), por exemplo, relaciona o direito à igualdade com a forma de exercício do governo e afirma que um "governo coercivo só é legítimo quando tenta mostrar preocupação igual com os destinos de todos aqueles que governa e respeito total pela responsabilidade pessoal dessas pessoas pelas suas próprias vidas".

A segunda parte da afirmação de Dworkin guarda relação com o modelo de atuação do Estado Liberal, no qual existia uma forte predominância dos direitos civis e políticos, tanto que a relação entre o direito privado e o direito público era nitidamente marcada pela prevalência do primeiro em face do segundo. Nesse período, a atuação do Estado era mínima, de modo a se garantir que cada pessoa fosse diretamente responsável pelo destino de sua vida e as regulamentações estatais ocorriam em áreas que se mostrassem imprescindíveis para a sua atuação. Em outras palavras, a função do direito era limitada a garantir o status negativo da liberdade do particular, de modo a determinar uma não atuação do Estado.

Já na primeira parte da afirmação de Dworkin, tem-se uma nítida influência do Estado Social. As esferas privadas, marcadas pela não atuação do Estado Liberal, sofreram grande alteração e a materialização dos direitos ganhou destaque no Estado Social por meio de um 
ideal de justiça unilateralmente distribuído pelo Leviatã. Nesse período histórico, a igualdade foi qualificada pela obrigação de se incluir grupos historicamente discriminados, em especial pelo fato desse paradigma estatal mostrar preocupação igual com os destinos de todos aqueles que governa.

Para que no Estado Democrático de Direito não ocorra a prevalência de um desses modelos de Estado, a legitimidade do governo deve se basear na tensão entre as premissas dos dois paradigmas para que um não sobressaia o outro e, com isso, não ocorra a violação do princípio de Kant.

Em relação ao direito à liberdade, Ronald Dworkin (2012, p. 374) constrói o seu conceito com base em duas liberdades que sempre foram apontadas pelos filósofos como formas opostas de exercício desse direito.

$\mathrm{Na}$ liberdade positiva, "as pessoas devem poder desempenhar um papel na sua própria governação coerciva" (DWORKIN, 2012 p. 374), o que se traduz na ideia de autogoverno presente no modelo democrático de exercício do poder.

Na liberdade negativa, "as pessoas devem estar livres do governo coercivo em relação a um nível substancial das decisões e atividades" (DWORKIN, 2012, p. 374), ou seja, a existência de algumas leis viola a independência ética porque negam às pessoas o poder de tomarem decisões sobre questões de essência ética, como é o caso da escolha (ou não) de uma religião, do exercício da cultura, do modo de se vestir, entre outros.

Nesse diapasão, a base moral de Dworkin é nitidamente uma base kantiana, capaz de relacionar em todos os níveis a moral e a ética, não como conflitantes entre si, mas como complementares e necessárias para o adequado exercício dos direitos fundamentais.

Existe, com isso, uma nítida relação entre ética e moral na construção da moral política, fundamento de legitimidade do Direito, que, ao ser estruturada na forma de árvore, condiciona a interpretação e o exercício do Direito a uma proposta metodológica que vai além da mera análise das leis ou das decisões tomadas no passado, limite natural do positivismo jurídico.

\section{CONCLUSÃO}


Ao construir a relação entre o Direito e a Moral, Ronald Dworkin propõe a superação do poder discricionário do magistrado no sentido de que a sua atuação somente pode ter uma postura: a busca de um resultado a partir do caso concreto e construído dentro de um sistema aberto de regras e princípios, com base valorativa, o qual parte da Constituição e dos direitos fundamentais. Esse é o fundamento de legitimidade para a aplicação do Direito pelo magistrado no Estado Democrático de Direito, que deve entender que nenhum dos seus atos é isolado no tempo ou no espaço, uma vez que deve se debruçar sobre o passado e projetar a repercussão de cada ato no futuro.

Desse modo, a proposta de Ronald Dworkin representa uma verdadeira virada metodológica para a aplicação do Direito ao reconhecer a inevitável abertura hermenêutica dessa ciência com a moral e outras ciências. Nem todas as pessoas são capazes de entender essa superação do positivismo, uma vez que distintas visões paradigmáticas ainda hoje condicionam a atuação dos magistrados, apesar de não se mostrarem adequadas ao Estado Democrático de Direito.

Essa dificuldade é trabalhada por Machado de Assis em seu conto. Ao final de "Ideias de Canário", quando o pássaro já voava em liberdade, Macedo chama o canário para conversar no antigo mundo dos dois, supostamente formado em sua residência pelo jardim, pela varanda e pela gaiola branca, o qual é prontamente refutado pelo pássaro. Macedo não foi capaz de perceber a evolução pela qual o mundo do canário havia passado, mostrando a existência de um nítido confronto de paradigmas.

No Direito não é diferente, e o novo horizonte de possibilidades que é o Estado Democrático de Direito reclama um aprendizado crítico do próprio ser humano para que seja capaz de evoluir nesse mundo construtivo, contestador e fraterno. Essa é uma nova luz, uma nova maneira de visualizar as práticas sociais ou jurídicas, um mundo que representa no conto o espaço infinito e o céu azul do canário, mas que ainda dá os seus primeiros passos nessa jovem Democracia que é o Brasil.

\section{REFERÊNCIAS}

ASSIS, Joaquim Maria Machado de. Ideias do Canário. Disponível em: <http://contobrasileiro.com.br/?p=305>. Acesso em: 9 out. 2014. 
BAUMAN, Zygmunt. O mal-estar da pós-modernidade. Tradução de Mauro Gama e Cláudia Martinelli Gama. Rio de Janeiro: Jorge Zahar, 1997. 272 p.

BENJAMIN, Cássio Corrêa; SOUZA, Eron Geraldo. O problema da interpretação em Kelsen. Revista da Faculdade de Direito da UFG, v.34, jan/jun. Goiás: UFG janeiro a junho de 2010, p. 132-148.

BOBBIO, Norberto. O positivismo jurídico: lições de filosofia do Direito. Rio de Janeiro: Ícone, 2006.

CAPPELLETTI, Mauro. O controle judicial de constitucionalidade das leis no Direito Comparado. Tradução de Aroldo Plínio Gonçalves. Porto Alegre: Sérgio Antonio Fabris, 1999. $141 \mathrm{p}$.

CARVALHO NETTO, Menelick de. Requisitos pragmáticos da interpretação jurídica sob o paradigma do Estado Democrático de Direito. Revista brasileira de Direito Comparado. Belo Horizonte: Mandamentos, v. 3, p. 573-586, 1999.

COURA, Alexandre de Castro. Sobre discricionariedade e decisionismo na interpretação e aplicação das normas em Kelsen. In: FARO, Julio Pinheiro; BUSSINGUER, Elda Coelho de Azevedo (Org.). A diversidade do pensamento de Hans Kelsen. Rio de Janeiro: Lumen Juris, 2013, p. 131-139.

; ZANOTTI, Bruno Taufner. Pós-positivismo jurídico e a teoria do direito como integridade de Ronald Dworkin. Revista Nomos. Fortaleza: UFC, v. 34.2, p. 53-69, 2014. Disponível em: < http://www.periodicos.ufc.br/>. Acesso em: 5 jan. 2015.

AZEVEDO; Silvagner Andrade de. Indeterminação do direito e discricionariedade judicial: pensando a crise do positivismo jurídico a partir de Kelsen, Hart e Dworkin. In: Alexandre de Castro Coura; Elda Coelho de Azevedo Bussinguer. (Org.). Direito, Política e Constituição: reflexões acerca da tensão entre constitucionalismo e democracia à luz do paradigma do Estado Democrático de Direito. 1ed.Curitiba: CRV, 2014, v. 1, p. 101-141.

CRETELlA Jr. J.; CRETEllA, Agnes. Vida e obra de Hans Kelsen. In: KELSEN, Hans. Teoria Pura do Direito: versão condensada pelo próprio autor. Trad. J. Cretella Jr. e Agnes Cretella. Baptista Machado. 4a . ed. rev. ampl. atual. São Paulo: Revista dos Tribunais, 2006, p. 17-18.

DWORKIN, Ronald. O império do direito. Tradução de Jefferson Luiz Camargo. São Paulo: Martins Fontes, 2007. 513 p.

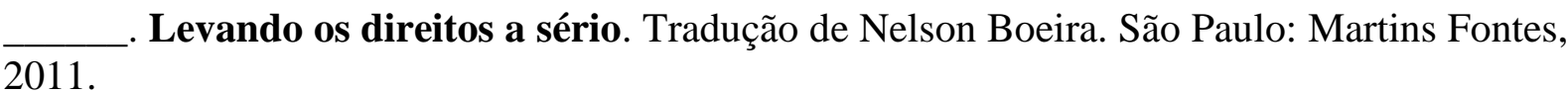
Justiça para Ouriços. Tradução de Pedro Elói Duarte. Coimbra: Almedina, 2012. 515 p. 
GADAMER, Hans-Georg. Verdade e método I: traços fundamentais de uma hermenêutica filosófica. Tradução de Flávio Paulo Meurer. $7^{\text {a }}$ ed. Petrópolis: Vozes, 2005.

KANT, Immanuel. Fundamentação da metafísica dos costumes e outros escritos. Tradução de Leopoldo Holzbach. São Paulo: Martin Claret, 2011.

KUHN, Thomas S. A estrutura das revoluções científicas. Tradução de Beatriz Vianna Boeira e Nelson Boeira. São Paulo: Perspectiva, 2001.

MACEDO Jr., Ronaldo Porto. Do xadrez à cortesia: Dworkin e a teoria do direito contemporânea. São Paulo: Saraiva, 2014.

STRECK, Lenio Luiz. Verdade e consenso. 4. ed. São Paulo: Saraiva, 2012a. 639 p.

É possível fazer Direito sem interpretar? 2012b. Disponível em: < http://www.conjur.com.br/2012-abr-19/senso-incomum-jurisprudencia-transita-entreobjetivismo-subjetivismo>. Acesso em: 9 out. 2014. 